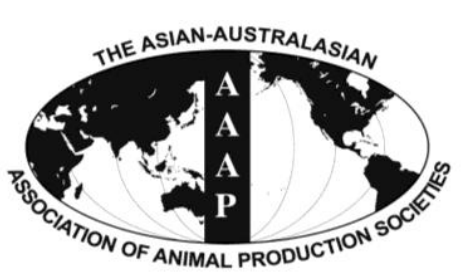

\begin{tabular}{c} 
Open Access \\
$\begin{array}{c}\text { Asian Australas. J. Anim. Sci. } \\
\text { Vol. 27, No. 1 : 19-23 January 2014 } \\
\text { http://dx.doi.org/10.5713/ajas.2013.13443 }\end{array}$ \\
\hline www.ajas.info \\
pISSN 101 1-2367 elSSN 1976-5517
\end{tabular}

\title{
Genetic Diversity of mtDNA D-loop Polymorphisms in Laotian Native Fowl Populations
}

\author{
K. Kawabe*, R. Worawut ${ }^{1}$, S. Taura, T. Shimogiri ${ }^{2}$, T. Nishida ${ }^{1}$, and S. Okamoto ${ }^{2}$ \\ Institute of Gene Research, Natural Science Centre for Research and Education, \\ Kagoshima University, Kagoshima 890-0065, Japan
}

\begin{abstract}
Here, we studied the genetic diversity of native fowls in Laos by analyzing a mitochondrial DNA (mtDNA) sequence polymorphism. A 546-bp fragment of the mtDNA D-loop region was sequenced in 129 chickens from the areas of Vientiane, Luang Prabang and Pakse. In total, 29 haplotypes were identified and formed five clades. Haplotype diversity and nucleotide diversity of the native fowls in Laos were $0.85536 \pm 0.0172$ and $0.010158 \pm 0.005555$, respectively. Although the Laotian native fowls were distributed across five clades, most of them were clustered in two main clades (A and B), which were originated in China. The other haplotypes were contained in clades D, F, and I, which originated from continental southeast Asia. These results suggest that multiple maternal lineages were involved in the origin of domestic chicken in Laos. Moreover, there appear to be at least two maternal lineages, one from China and the other from the southeast Asian continent. (Key Words: Native Fowl, Genetic Variability, mtDNA, Maternal Origin)
\end{abstract}

\section{INTRODUCTION}

Laos is a tropical landlocked country that shares borders with Thailand, Cambodia, Vietnam, China, and Myanmar, and is located between latitudes 14 and 23 and longitudes 100 and 108. The country's borders with Thailand and Myanmar are formed by the Mekong River, whose source is in Quinghai Province, China. The terrain in over $70 \%$ of the country is composed of mountains and plateaus. There are many kinds of native fowls in Asia. Most of them have not been improved and have lower productive performance than the improved western breeds. In Laos, there are many kinds of native fowls, and farmers rear small flocks of native chickens as an important protein source. There are also many improved breeds that have been introduced from foreign countries, mainly Thailand. Pure native fowl in

\footnotetext{
* Corresponding Author: Kotaro Kawabe. Tel: +81-99-285-3591, Fax: +81-99-285-3582, E-mail: kawabe@gene4.agri.kagoshimau.ac.jp

${ }^{1}$ Faculty of Veterinary Medicine, Kasetsart University, Bangkok, Thailand.

${ }^{2}$ Faculty of Agriculture, Kagoshima University, Kagoshima, Japan.

Submitted Jul. 22, 2013; Accepted Sept. 5, 2013; Revised Sept. 21, 2013
}

Laos are gradually decreasing. Because the native chicken populations possess genes that modern breeds have lost, it is very important to retain these genes for the future. Thus, we need to survey the genetic characteristics of native fowls and evaluate their genetic resources. However, there has been little research on Laotian native fowls. One of the few studies was done by Okamoto et al. (1996), who reported the gene constitution of Laotian native fowl by analyzing blood protein polymorphisms.

Many researchers have reported mitochondrial DNA (mtDNA) polymorphisms in various animal populations to clarify the ancestral lineage or to compare populations. A number of studies have been carried out to investigate the ancestors of modern chickens by examing mtDNA polymorphisms. Akishinonomiya et al. (1996) suggested a monophyletic origin of domestic chickens from one of the red jungle fowl subspecies Gallus gallus gallus, and proposed that a single domestication event occurred in Thailand and adjacent countries. In contrast, Kanginakudru et al. (2008) reported that two other subspecies, G. $g$. spadiceus and G. g. murghi, also contributed to the lineage that gave rise to domestic chickens. Other reports described multiple and independent domestication events in south China, southeast Asia and the Indian subcontinent (Liu et al., 
2006; Oka et al., 2007). Liu et al. (2006) revealed nine divergent clades related to the geographical distribution of a wide range of domestic chickens in Eurasian regions. Oka et al. (2007) also identified seven clades in Japanese native chickens, of which four clades are identical to four clades described by Liu et al. (2006). Muchadeyi et al. (2008) arranged these clade classification approaches by Liu et al. (2006) and Oka et al. (2007) to apply Zimbabwean native chickens analysis, and suggested that a third maternal lineage excluded Zimbabwean and other African chickens and clustered with haplotypes presumably originating from China. Cuc et al. (2011) also applied this strategy to Vietnamese native breeds and suggested that they have originated from multiple maternal lineages from several regions of China and surrounding regions.

The present study was conducted to clarify the genetic diversity of Laotian native fowl populations. We also tried to determine the degree of shared maternal mtDNA haplotypes among populations of Laotian native fowls and, hence, reveal maternal lineages of origin.

\section{MATERIALS AND METHODS}

\section{Birds}

A total of 129 native chicken samples were collected for this study. The native fowls were collected 54 birds from Vientiane, 42 from Luang Prabang, and 33 from Pakse.

\section{mtDNA amplification and sequencing}

Total DNAs were extracted from blood samples by using a standard phenol-chloroform extraction. A fragment of 546-bp from the mtDNA D-loop region was amplified using PCR. The primers used were L16750 (5'AGGACTACGGCTTGAAAAGC-3'; Akishinonomiya et al., 1994) and H522 (5'- ATGTGCCTGACCGAGGAACCAG 3'; Liu et al., 2006). The numbers in the primer names indicate the homologous positions of the $3^{\prime}$ end of the primers on the mtDNA sequence described by Desjardins and Morais (1990). The PCR reaction was performed using the GeneAmp PCR System 9700 (Applied Biosystems, CA, USA) and the following mixture consisted of $100 \mathrm{ng}$ of template DNA, $1 \times \mathrm{PCR}$ reaction buffer, 4 pmol of each primer, $400 \mu \mathrm{mol}$ of each dNTPs, and $1 \mathrm{U}$ of exTaq polymerease (TaKaRa, Otsu, Japan). The thermal profile included an initial denaturation at $94^{\circ} \mathrm{C}$ for 1 min followed by 30 cycles, each of which included denaturation at $94^{\circ} \mathrm{C}$ for $1 \mathrm{~min}$, annealing at $60^{\circ} \mathrm{C}$ for $1 \mathrm{~min}$, and extension at $72^{\circ} \mathrm{C}$ for $1 \mathrm{~min}$, with a final extension step at $72^{\circ} \mathrm{C}$ for 7 min. The PCR products were isolated from $1 \%$ agarose gels and purified with Mag Extractor (TOYOBO, Osaka, Japan). The BigDye terminator cycle sequencing kit v. 3.1 (Applied Biosystems) and ABI Prism 3130xl genetic analyzer sequencer (Applied Biosystems) were used for sequence analysis.

\section{Data analysis}

Multiple alignment analysis was carried out using the Clustal X version 2.1 computer software (Larkin et al., 2007). The position and number of polymorphic sites and of corresponding haplotypes were calculated using MEGA v.5.2.1 (Tamura et al., 2011). Nucleotide diversity (Nei and $\mathrm{Li}, 1979$ ) and haplotype diversity (Nei, 1987) were estimated using ARLEQUIN v.3.5.1.3 (Excoffier et al., 2010). A median joining network (Bandelt et al., 1999) was constructed using NETWORK 4.611 software (Fluxus Technology Ltd.) to classify the haplotypes under the settings described by Cuc et al. (2011) into nine clades, following Liu et al. (2006), and three clades, following Oka et al. (2007). The list of haplotypes used and the corresponding GenBank accession numbers are provided in Table 1.

Table 1. Haplotype names and accession numbers of chicken mtDNA sequences used in this study

\begin{tabular}{lll}
\hline Haplotype & GenBank accession No. & Reference \\
\hline A1 -A10 & & This study \\
B1 - B12 & & This study \\
D1 - D4 & & This study \\
F1 -F2 & & This study \\
I & This study \\
Liu_A1 & AB114069 & Liu et al. (2006) haplotype A1 \\
Liu_B1 & AB007744 & Liu et al. (2006) haplotype B1 \\
Liu_C1 & AY114070 & Liu et al. (2006) haplotype C1 \\
Liu_D1 & AB114076 & Liu et al. (2006) haplotype D1 \\
Liu_E1 & AF512285 & Liu et al. (2006) haplotype E1 \\
Liu_F1 & AF512288 & Liu et al. (2006) haplotype F1 \\
Liu_G1 & D82904 & Liu et al. (2006) haplotype G1 \\
Liu_H1 & AB009434 & Liu et al. (2006) haplotype H1 \\
Liu_I1 & AB268535 & Liu et al. (2006) haplotype I1 \\
Oka_D6 & AB268545 & Oka et al. (2007) haplotype D6 \\
Oka_G1 & AB268543 & Oka et al. (2007) haplotype G1 \\
Oka_F1 & & Oka et al. (2007) haplotype F1
\end{tabular}


Table 2. The identified haplotypes with the mitochondrial D-loop sequence polymorphisms in Laotian native fowl populations

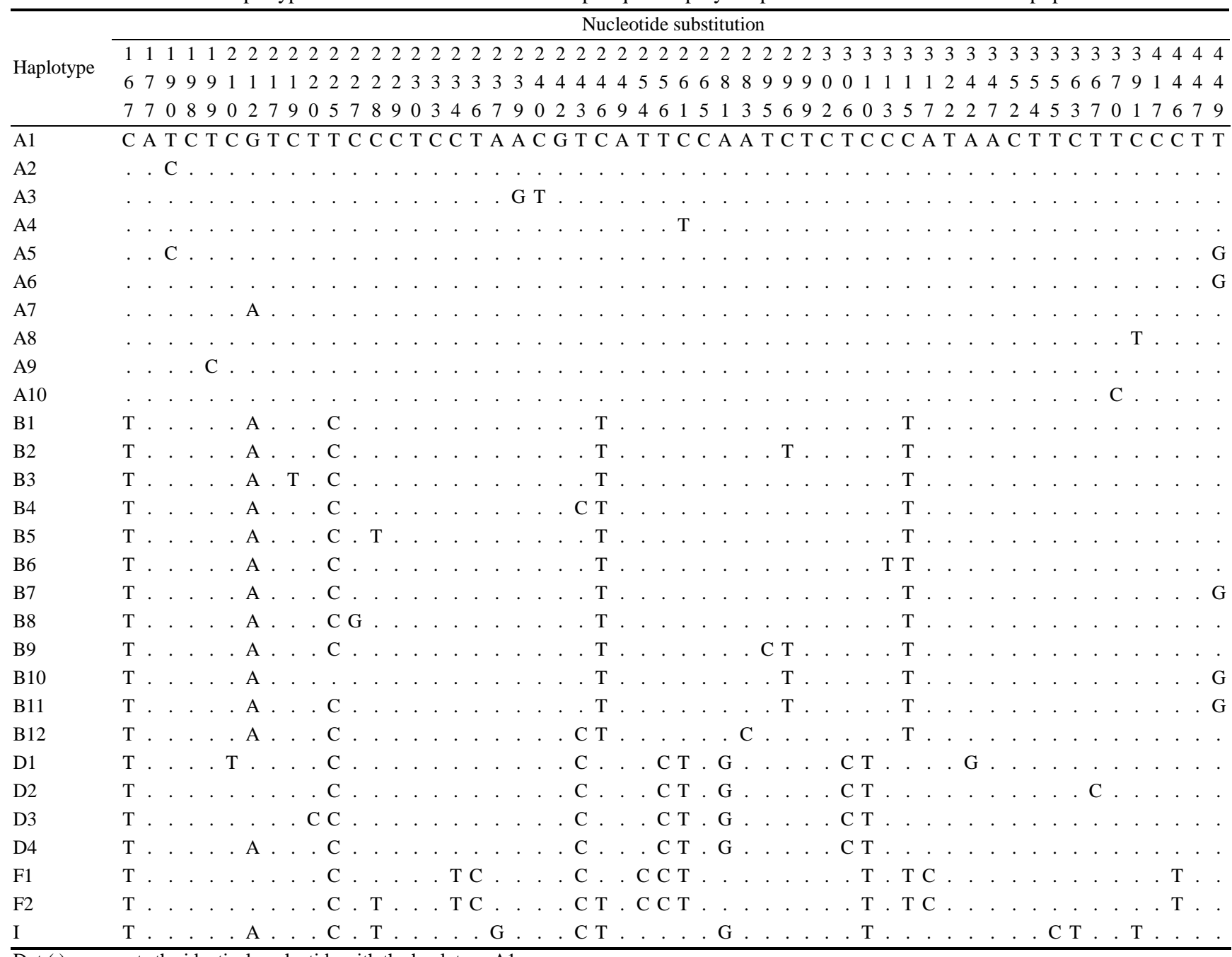

Dot (.) represents the identical nucleotide with the haplotype A1.

\section{RESULTS AND DISCUSSION}

\section{Genetic diversity and haplotype classification}

A total number of 37 variable sites were identified (Table 2). No insertions or deletions were detected in our sequences. The calculated number of polymorphic sites and haplotypic diversity of three populations of Laotian natives are shown in Table 3. The haplotypic diversity ranged from 0.5183 (Luang Prabang) to 0.8798 (Vientiane), although the differences between populations were small. Laotian native fowls showed a higher value of haplotypic diversity than did Zimbabwean (0.29 to 0.78: Muchadeyi et al., 2008),
Vietnamese (0.62 to 0.94: Cuc et al., 2011) or Korean (0.59 to 0.82 : Hoque et al., 2013) fowls. The nucleotide diversity observed in this study ranged from 0.0007706 (Luang Prabang) to 0.014519 (Pakse) and was almost the same value as that of Korean native chickens (Hoque et al., 2013). These results suggest that Laotian native chicken populations have relatively high genetic diversity.

\section{Network analysis and haplotype distribution}

The 29 haplotypes observed in the Laotian native fowls were clustered into five clades (Figure 1). The haplotypes A1, B1, D1, F1, and I in this study were the same as the

Table 3. Polymorphic sites, haplotype and nucleotide diversity of three Laotian native fowl populations

\begin{tabular}{lccccc}
\hline Locality & $\mathrm{n}$ & $\begin{array}{c}\text { No. of } \\
\text { polymorphic sites }\end{array}$ & $\begin{array}{c}\text { No. of } \\
\text { haplotypes }\end{array}$ & Haplotype diversity $( \pm$ SD $)$ & Nucleotide diversity $( \pm$ SD) \\
\hline Vientiane & 54 & 23 & 20 & $0.8798 \pm 0.0268$ & $0.008957 \pm 0.005033$ \\
Luang Prabang & 42 & 10 & 7 & $0.8153 \pm 0.0296$ & $0.007706 \pm 0.004448$ \\
Pakse & 33 & 26 & 10 & $0.8466 \pm 0.0350$ & $0.014519 \pm 0.007823$ \\
Total & 129 & 37 & 29 & $0.8536 \pm 0.0172$ & $0.010158 \pm 0.005555$ \\
\hline
\end{tabular}




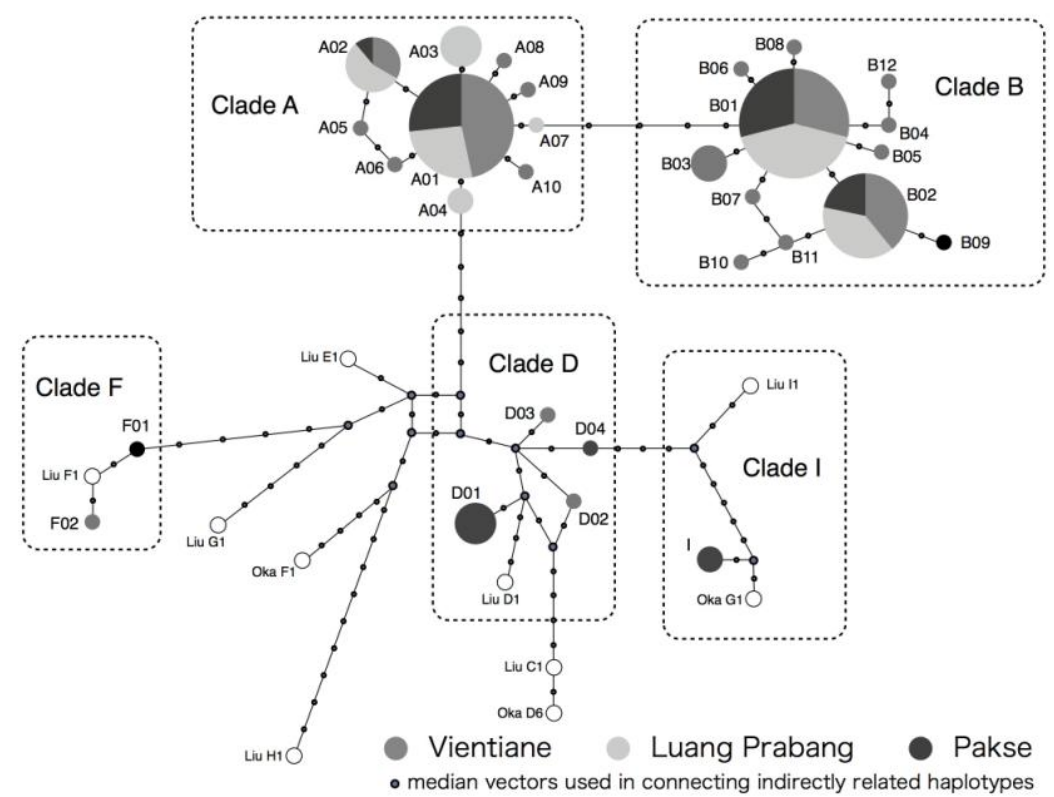

Figure 1. Median network profile of the mtDNA Dloop haplotypes observed in the present study. Data are merged with sequences of major haplotypes described from Liu et al. (2006) and Oka et al. (2007). The circle size corresponds to haplotype frequency.

partial sequence of each haplotype A1, B1, D1, F1, and I1 from the clades described by Liu et al. (2006). We did not detect the five haplotypes C1, D1, E1, F1, and G1 described by Liu et al. (2006) or the three haplotypes D6, F1, and G1 described by Oka et al. (2007) in the study populations. Most individuals were classed in clades A and B whereas clades D, F, and I consisted of only a small number of individuals (Table 4).

The formation of the network profile of Laotian native fowl populations was similar to that of Vietnamese native chicken breeds reported by Cuc et al. (2011). However, clades $\mathrm{C}, \mathrm{E}$, and $\mathrm{G}$, which are major haplotypes in Vietnamese chickens, were not observed in the Laotian populations. Within clades A and B, the major haplotypes were A1 and B1, composing 59\% and $46 \%$ of each clade, respectively. Using the skeleton of supposed regions of domestication, this finding suggests that two maternal lineages dominate in the Laotian native fowls, which presumably originated from Yunnan and the surrounding area in China (Liu et al., 2006). A total of $80 \%$ of the Pakse population belonged to clades D, F, and I. Liu et al. (2006) and Oka et al. (2007) suggested that clade D has its roots in southeast, south and southwest China and/or the surrounding area (i.e., Vietnam, Thailand, Myanmar and India). A small number of chickens in the Pakse population were also distributed in clade I, originating from continental southeast Asia (Liu et al., 2006). Both Vientiane and Luang Prabang are northern areas in Laos, and they are close to China. However, Pakse area is located in the southern part of Laos is close to Vietnam. Therefore, our results are consistent with the geographical relationship of these populations.
Table 4. Distribution of mtDNA D-loop haplotypes in three populations of Laotian native fowls

\begin{tabular}{|c|c|c|c|c|}
\hline Haplotype & Vientiane & $\begin{array}{c}\text { Luang } \\
\text { Prabang }\end{array}$ & Pakse & Total \\
\hline$\overline{\mathrm{A} 1}$ & 14 & 8 & 8 & 30 \\
\hline $\mathrm{A} 2$ & 3 & 5 & 1 & 9 \\
\hline A3 & & 4 & & 4 \\
\hline A4 & & 2 & & 2 \\
\hline A5 & 1 & & & 1 \\
\hline A6 & 1 & & & 1 \\
\hline A7 & & 1 & & 1 \\
\hline A8 & 1 & & & 1 \\
\hline A9 & 1 & & & 1 \\
\hline A10 & 1 & & & 1 \\
\hline B1 & 9 & 13 & 9 & 31 \\
\hline B2 & 9 & 9 & 5 & 23 \\
\hline B3 & 4 & & & 4 \\
\hline B4 & 1 & & & 1 \\
\hline B5 & 1 & & & 1 \\
\hline B6 & 1 & & & 1 \\
\hline B7 & 1 & & & 1 \\
\hline B8 & 1 & & & 1 \\
\hline B9 & & & 1 & 1 \\
\hline B10 & 1 & & & 1 \\
\hline B11 & 1 & & & 1 \\
\hline B12 & 1 & & & 1 \\
\hline D1 & & & 4 & 4 \\
\hline D2 & 1 & & & 4 \\
\hline D3 & 1 & & & 1 \\
\hline D4 & & & 1 & 1 \\
\hline $\mathrm{F} 1$ & & & 1 & 1 \\
\hline $\mathrm{F} 2$ & & & 1 & 1 \\
\hline I & & & 2 & 2 \\
\hline Total & 54 & 42 & 33 & 129 \\
\hline
\end{tabular}




\section{REFERENCES}

Akishinonomiya, F., T. Miyake, S. Sumi, M. Takada, S. Ohno, and N. Kondo. 1994. One subspecies of the red junglefowl (Gallus gallus gallus) sufficies as the matriarchic ancestor of all domestic breeds. Proc. Natl. Acad. Sci. USA 91:12505-12509.

Akishinonomiya, F., T. Miyake, M. Takada, R. Shingu, T. Endo, T. Gojobori, N. Kondo, and S. Ohno. 1996. Monophyletic origin and unique dispersal patterns of domestic fowls. Proc. Natl. Acad. Sci. USA 93:6792-6795.

Bandelt, H. J, P. Forster, and A. Röhl. 1999. Median-joining networks for inferring intraspecific phylogenies. Mol. Biol. Evol. 16:37-48.

Cuc, N. T. K., H. Simianer, L. F. Groeneveld, and S. Weigend. 2011. Multiple maternal lineages of vietnamese local chickens inferred by mitochondrial D-loop sequences. Asian-Aust. J. Anim. Sci. 24:155-161.

Desjardins, P. and R. Morais. 1990. Sequence and gene organization of the chicken mitochondrial genome: a novel gene order in higher vertebrates. J. Mol. Biol. 212:599-634.

Excoffier, L. and H. E. L. Lischer. 2010. Arlequin suite ver 3.5: A new series of programs to perform population genetics analyses under Linux and Windows. Mol. Ecol. Res. 10:564567.

Hoque, M. R., N. R. Choi, H. Sultana, B. S. Kang, K. N. Heo, S. K. Hong, C. Jo, and J. H. Lee. 2013. Phylogenetic analysis of a privately-owned Korean native chicken population using mtDNA d-loop variations. Asian-Aust. J. Anim. Sci. 26:157162.
Kanginakudru, S., M. Metta, R. D. Jakati, and J. Nagaraju. 2008. Genetic evidence from Indian red jungle fowl corroborates multiple domestication of modern day chicken. BMC Evol. Biol. 8:174.

Larkin M. A., G. Blackshields, N. P. Brown, R. Chenna, P. A. McGettigan, H. McWilliam, F. Valentin, I. M. Wallace, A. Wilm, R. Lopez, J. D. Thompson, T. J. Gibson, and D. G. Higgins. 2007. Clustal $\mathrm{W}$ and Clustal $\mathrm{X}$ version 2.0. Bioinformatics 23:2947-2948.

Liu, Y. P., G. S. Wu, Y. G. Yao, Y. W. Miao, G. Luikart, M. Baig, A. Beja-Pereira, Z. L. Ding, M. G. Palanichamy, and Y. P. Zhang. 2006. Multiple maternal origins of chickens: Out of the Asian jungles. Mol. Phylogenet. Evol. 38:12-19.

Muchadeyi, F. C., H. Eding, H. Simianer, C. B. A. Wollny, E. Groeneveld, and S. Weigend. 2008. Mitochondrial DNA Dloop sequences suggest a Southeast Asian and Indian origin of Zimbabwean village chickens. Anim. Genet. 39:615-622.

Nei, M. 1987. Molecular Evolutionary Genetics Columbia University Press: New York, USA.

Oka, T., Y. Ino, K. Nomura, S. Kawashima, T. Kuwayama, H. Hanada, T. Amano, M. Takada, N. Takahatam Y. Hayashi, and F. Akishinonomiya 2007. Analysis of mtDNA sequences shows Japanese native chickens have multiple origins. Anim. Genet. 38:287-293.

Okamoto, S., N. Tsunekawa, Y. Kawamo, R. Worawut, K. Kawabe, Y. Maeda, and T. Nishida. 1999. Blood protein polymorphisms of native fowls in Laos. Asian-Aus. J. Anim. Sci. 12:10111014.

Tamura, K., D. Peterson, N. Peterson, G. Stecher, M. Nei, and S. Kumar. 2011. MEGA5: molecular evolutionary distance, and maximum parsimony methods. Mol. Biol. Evol. 28:2731-2739. 